\title{
Saline is a more appropriate solution for microvesicles for flow cytometric analyses
}

\author{
Xing Xin ${ }^{1, *}$, Peiling Zhang ${ }^{1, *}$, Xing Fu ${ }^{1}$, Xia Mao ${ }^{1}$, Fankai Meng ${ }^{1}$, Ming Tian ${ }^{1}$, Xiaojian \\ Zhu ${ }^{1}$, Hanying Sun ${ }^{1}$, Li Meng ${ }^{1}$ and Jianfeng Zhou ${ }^{1}$ \\ ${ }^{1}$ Department of Hematology, Tongji Hospital, Tongji Medical College, Huazhong University of Science and Technology, Wuhan \\ 430030, P. R. China \\ *These authors have contributed equally to this work \\ Correspondence to: Xiaojian Zhu, email: zhuxiaojian@hust.edu.cn \\ Jianfeng Zhou, email: jfzhou@tjh.tjmu.edu.cn \\ Keywords: phosphate-buffered saline, saline, flow cytometry, microvesicles
}

Received: September 20, $2016 \quad$ Accepted: February 20, $2017 \quad$ Published: March 07, 2017

Copyright: Xin et al. This is an open-access article distributed under the terms of the Creative Commons Attribution License (CC-BY), which permits unrestricted use, distribution, and reproduction in any medium, provided the original author and source are credited.

\section{ABSTRACT}

Microvesicles (MVs) are carriers of molecular and oncogenic signatures present in subsets of tumor cells and tumor-associated stroma, and a focus of cancer research. Although methods to detect MVs are mature, we were concerned that the buffer used could lead to false results when quantitating MVs by flow cytometry. In this work, we detected MVs by flow cytometry withthree different solutions: water, saline, and phosphate-buffered saline (PBS). The results demonstrated that PBS, when reacted with annexin $V$ binding buffer, produced nano-sized vesicles even when there were no MVs in the sample. No similar events occurred in the saline and water groups $(P<$ 0.01). Annexin $V$ positive rate increased significantly when PBS was used as the buffer, compared to saline and water. These false negative results were also observed when we quantified some markers of MVs such as CD3 and CD19. A probable explanation for these findings is the production of insoluble $\mathrm{Ca}\left(\mathrm{H}_{2} \mathrm{PO}_{4}\right)_{2}$ or $\mathrm{Ca}_{3} \mathrm{PO}_{4}$ from calcium in the binding buffer and phosphate in PBS. Thus, considering the osmotic pressure of water, we suggest that saline is a more suitable buffer when counting MVs by flow cytometry.

\section{INTRODUCTION}

Cellular microvesicles (MVs), $0.1-1 \mu \mathrm{m}$ in size, are released by various cell types, especially cancer cells that are undergoing stress and activation [1-3]. During recent decades, extensive research revealed that MVs carry their parental cell proteins, lipids, and nucleic acids, which may be transferred between cells [4-6]. MV-mediated cargo transfer to adjacent or remote cells affects tumor progression and provides a potential source of disease-related biomarkers [7]. Multiple studies have demonstrated that tumor cells may locate to undetectable sites but their MVs circulate in the blood, transporting information about the cancer [1-3]. Although the understanding of MV biology remains a major challenge, their characteristics create new opportunities for advances in cancer diagnostics and therapeutics. Such information suggests the possibility of using MVs in biological fluids as markers of cancer pathology, as more feasible "liquid-biopsy" material to gain diagnostic information, and to follow disease progression and the response to clinical treatment through a simple blood test or cerebrospinal fluid collection [1, 3, 7-9].

Uniform methods to isolate and identify MVs are not yet defined. Electron microscopy, atomic force microscopy, nanoparticle tracking analysis, and flow cytometry have been reported in many studies [10]. Among all, flow cytometry is effective for high-throughput quantification and multiparameter characterization of MVs [11-14]. Most researchers have confirmed the presence of MVs by assessing annexin V-positive vesicles using phosphate-buffered saline (PBS). However, we believe that using the annexin V binding buffer with PBS could generate numerous nano-sized vesicles that would seriously affect quantification of these structures. The aim of the current study was to investigate whether mixing the annexin V binding buffer with PBS modified the flow cytometry results. 


\section{RESULTS}

\section{Detection of MVs by electron and fluorescence microscopy}

K562 cells were observed by scanning electron microscopy (SEM) and transmission electron microscopy (TEM) (Figure 1A, 1B). Extracellular vesicles were visible on the surface of K562 cells through SEM (Figure 1A). The MV pellet was observed by TEM and they exhibited circular structures of different sizes with a bilayer (Figure 1C, 1D). Most vesicles were less than $1 \mu \mathrm{m}$ in diameter. PKH67-labeled MVs were observed directly by fluorescence microscopy (Figure 1E). PKH26-labeled MVs were devoured by human umbilical vein endothelial cells (HUVECs) after $12 \mathrm{~h}$ (Figure 1F).

\section{Annexin $\mathrm{V}$ binding buffer mixed with PBS generated nano-sized vesicles}

Initially, we discriminated sizes by flow cytometry using fluorescent microbeads of $0.22,0.45,0.88$, and $1.34-\mu \mathrm{m}$ diameters. The size position of the MV gate was assessed in forward versus side scatter dot plots
(Figure 2A, 2B). Flow cytometric analysis demonstrated that the majority of MVs were smaller than the 1.34$\mu \mathrm{m}$ beads. All gating events were also analyzed for phosphatidylserine (PS) by studying annexin V binding to distinguish true events (annexin $\mathrm{V}$ positive) from background noise. To detect nano-sized vesicles generated by mixing the annexin $\mathrm{V}$ binding buffer with PBS using flow cytometry, we used blank control groups containing water, saline, and PBS. To exclude pre-existing nano-sized vesicles from the blank and annexin $\mathrm{V}$ binding buffer solutions, we initially double-filtered the solutions through a $0.22-\mu \mathrm{m}$ filter and then determined MV-sized vesicle counts by flow cytometry. MVs from K562 cells were analyzed at the same time as a positive control. The number of events recorded during $30 \mathrm{~s}$ by flow cytometry were as follows: $30,120 \pm 3041$ for MVs isolated from K562 cells, $225 \pm 101$ for water, $340 \pm 197$ for PBS, $363 \pm 181$ for annexin $\mathrm{V}$ binding buffer, and $308 \pm 151$ for saline $(P<$ 0.0001 for $\mathrm{K} 562$ cells vs. all other groups) (Figure 2C-2H)

For further confirmation that PBS mixed with annexin $\mathrm{V}$ binding buffer could generate nano-sized vesicles, water, saline, and PBS were mixed with annexin $\mathrm{V}$ binding buffer. The counts of nano-sized vesicles from each group were $140 \pm 92$ (water), $165 \pm 87$ (water with
A

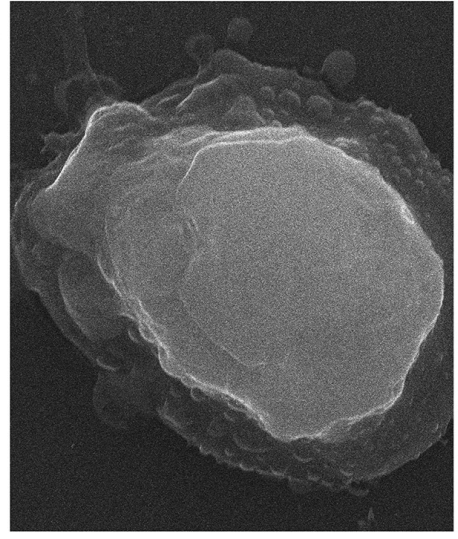

B

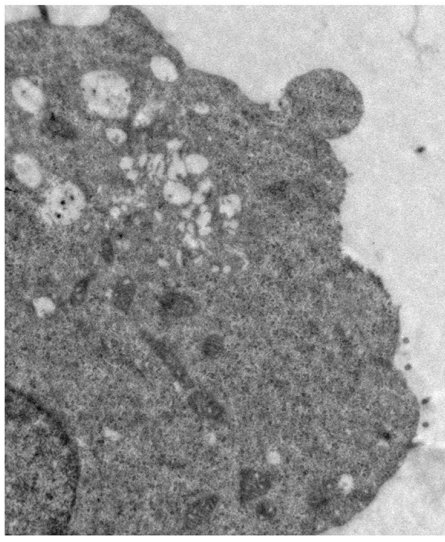

D

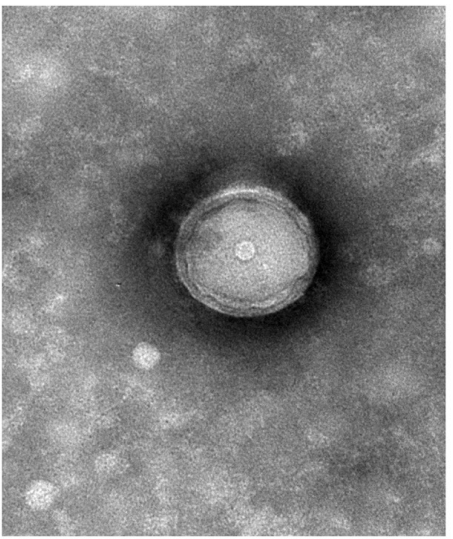

E

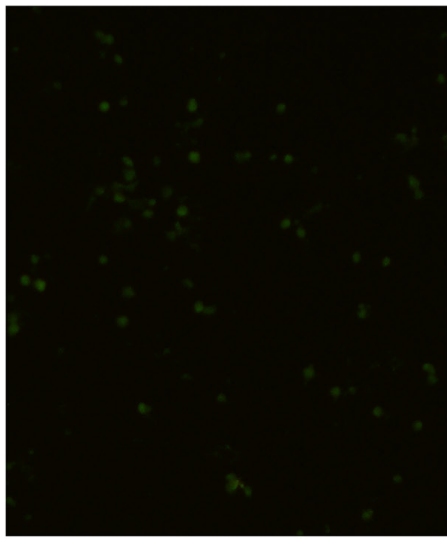

C

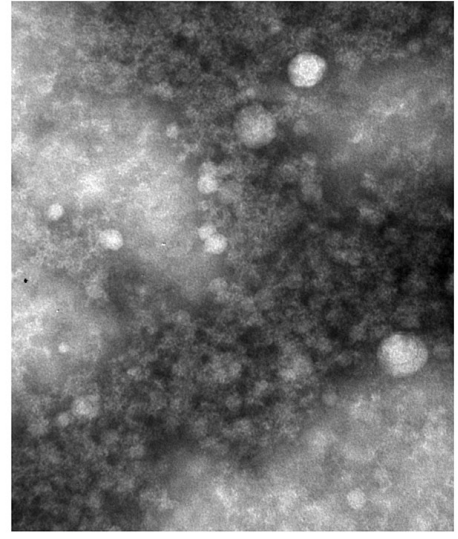

$\mathrm{F}$

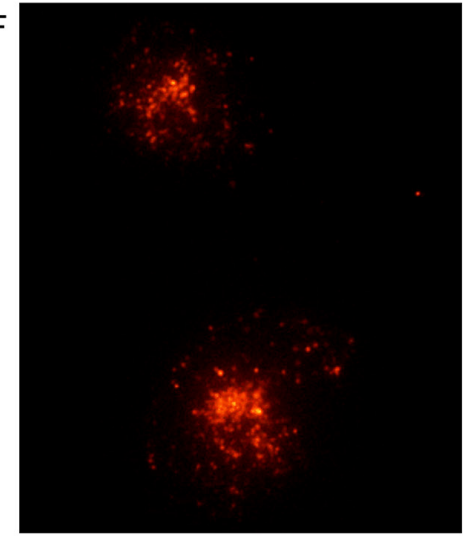

Figure 1: Fluorescent labeling and electron microscopy of microvesicles (MVs). K562 cells were observed by scanning (A) and transmission (B) electron microscopy. MVs were observed by transmission electron microscopy (C, D). (E) MVs were labeled directly by PKH67. (F) MVs labeled by PKH26 were devoured by human umbilical vein endothelial cells after $12 \mathrm{~h}$. 
annexin $\mathrm{V}$ binding buffer), $131 \pm 50$ (saline), $93 \pm 79$ (saline with annexin V binding buffer), $126 \pm 76$ (PBS), and 28,551 \pm 5010 (PBS with annexin V binding buffer). The counts of nano-sized vesicles in tubes of PBS with annexin $\mathrm{V}$ binding buffer were significantly different (n $=5, P<0.0001)$. There was no significant difference between the other groups $(\mathrm{n}=5, P=0.3310$, and $P=$ 0.4229 , respectively) (Figure 3 ).

To investigate whether the nano-sized vesicles affected the results of surface labeling on MVs, we used isotype-control IgG1-fluorescein isothiocyanate (FITC), -allophycocyanin (APC), -phycoerythrin (PE), and annexin $\mathrm{V}$ antibodies. The results were similar with all antibodies when counting nano-sized vesicles in water (n $=5, P>0.05$, Figure $4 \mathrm{~A})$. The counts of nano-sized vesicles in the saline group were $138 \pm 60$ and $156 \pm$ $69,138 \pm 70$ and $142 \pm 36,238 \pm 82$ and $307 \pm 90$, and $260 \pm 300$ and $330 \pm 265$ with the IgG1-FITC, -APC, -PE, and annexin $\mathrm{V}$ antibodies, without and with annexin $\mathrm{V}$ binding buffer, respectively $(\mathrm{n}=5, P>0.05$, Figure 4B). The numbers of nano-sized vesicles in the PBS group were $159 \pm 50$ and 43,291 $\pm 4920,162 \pm 63$ and
$46,012 \pm 3200,389 \pm 79$ and 41,088 \pm 5360 , and $210 \pm$ 250 and 50,190 \pm 6548 in the IgG1-FITC, -APC, -PE, and annexin $\mathrm{V}$ antibodies, without and with annexin $\mathrm{V}$ binding buffer, respectively $(\mathrm{n}=5, P<0.0001$, Figure 4C, 4D).

\section{Annexin V binding buffer mixed with PBS generated nano-sized vesicles and increased the false positive results when analyzed by flow cytometry}

For analysis of the nano-sized vesicles generated by mixing PBS with annexin V binding buffer, comparisons were made to MVs isolated from K562 cells. We selected the CD3-FITC, CD19-APC, annexin V-FITC, IgG1-FITC, IgG1-PE, and IgG1-APC antibodies to stain the MVs. Annexin $\mathrm{V}$ binding buffer was added to every sample. Nano-sized vesicles in the PBS group were significantly elevated compared to the saline group (Figure 5) (Supplementary Table 1). The positive rates in PBS group were also increased compared to the saline group (Figure 6) (Supplementary Table 1).
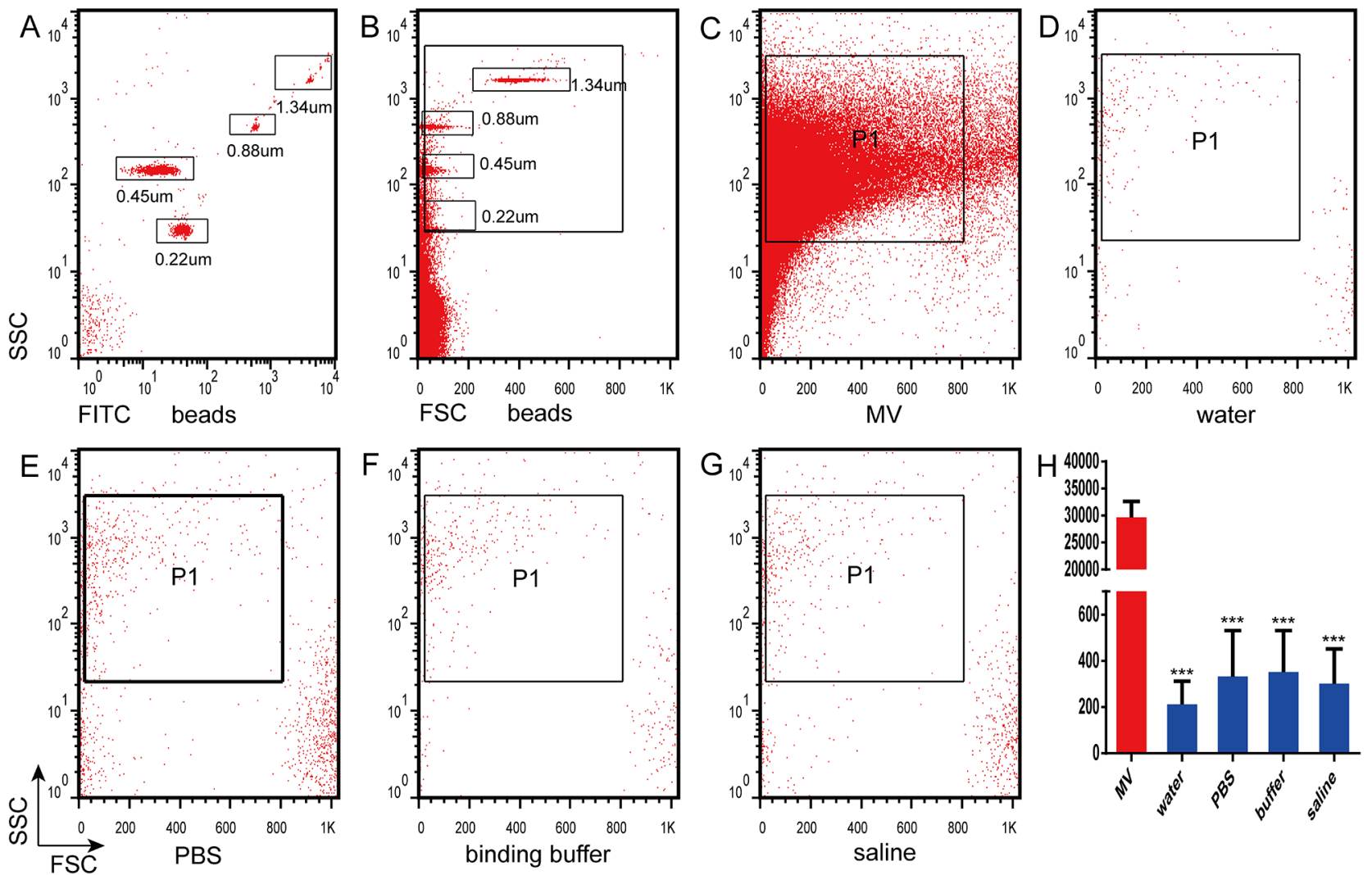

Figure 2: Analysis of nanoparticles by flow cytometry. (A) Nanoparticles were analyzed by flow cytometry based on fluorescein isothiocyanate fluorescence and side scatter count (SSC). (B) Fluorescent nanoparticles were analyzed by flow cytometry according to the SSC and forward scatter count (FSC). Nanoparticle counts were determined by flow cytometry in (C) microvesicles (MVs), (D) water $\left(\mathrm{H}_{2} \mathrm{O}\right)$, (E) phosphate-buffered saline (PBS), (F) annexin V binding buffer (binding buffer), and (G) saline. (H) Quantitation of the counts in $\mathrm{C}-\mathrm{G}$. 

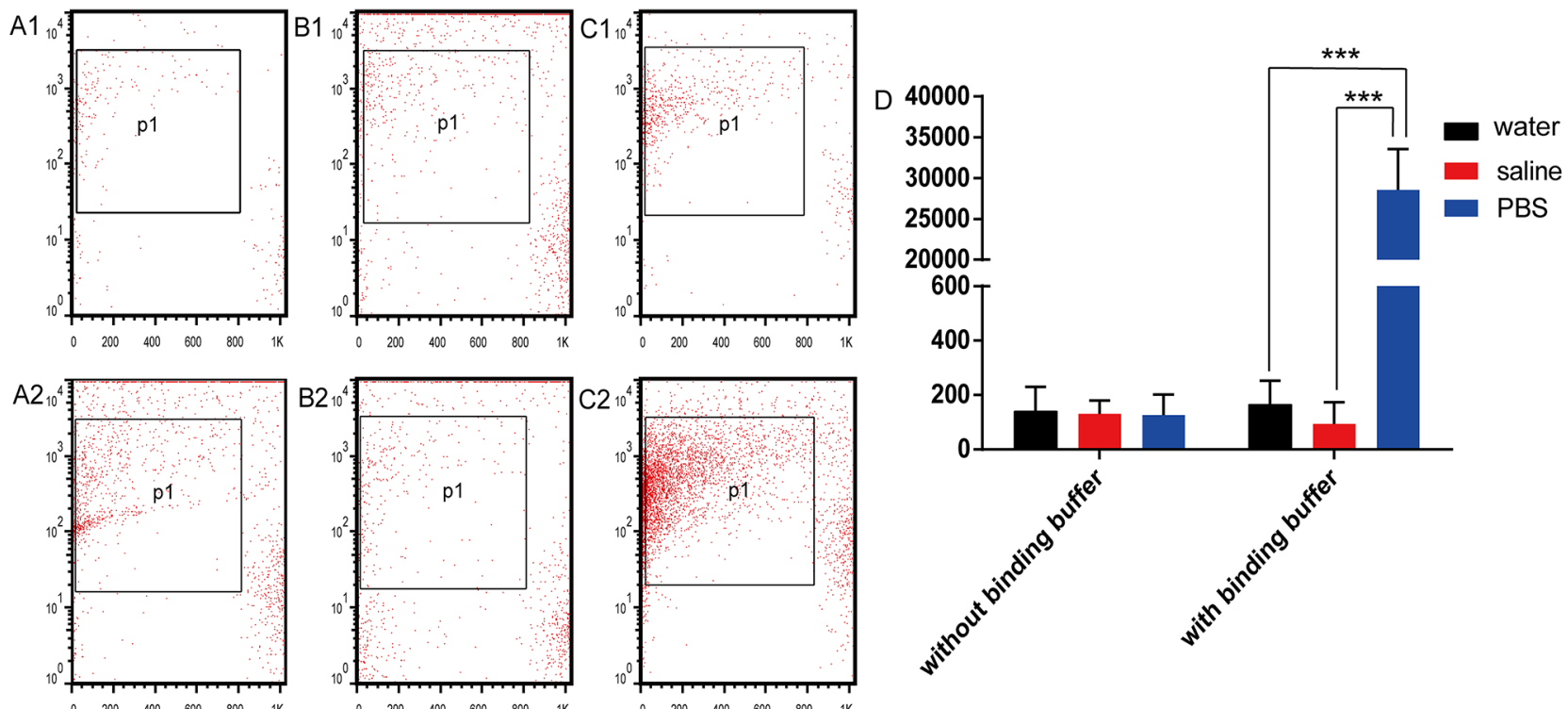

Figure 3: Generation of nanovesicles with and without annexin $\mathbf{V}$ binding buffer. Nanovesicles generated by (A1) water, (B1) saline, and (C1) phosphate-buffered saline (PBS) without annexin V binding buffer were analyzed by flow cytometry. Nanovesicles generated by (A2) water, (B2) saline, and (C2) PBS with annexin V binding buffer were analyzed by flow cytometry. (D) Quantitation of the flow cytometry results.
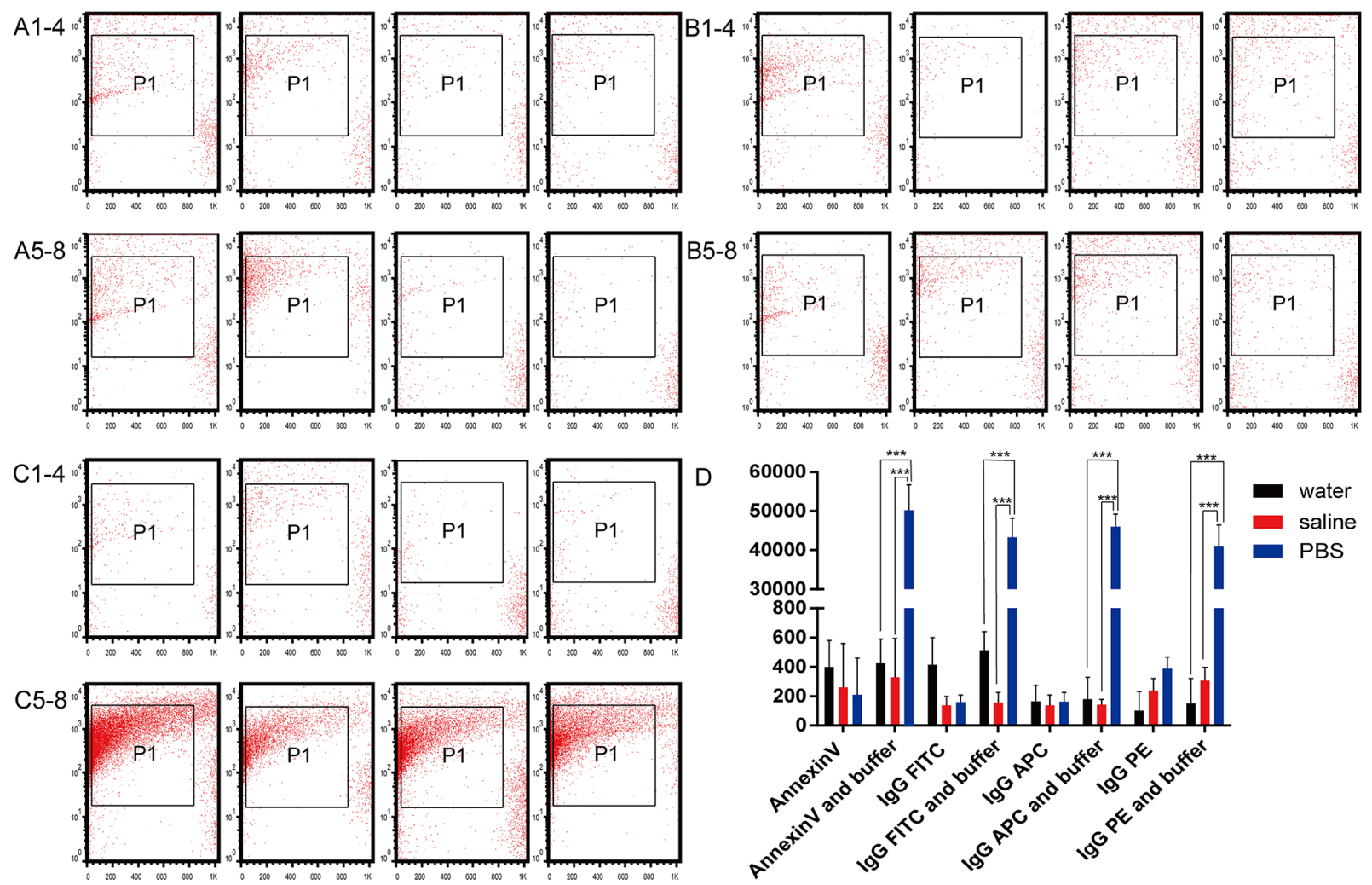

Figure 4: Effects of isotype control antibodies on nanovesicle counts. Nanovesicle counts without annexin $V$ binding buffer in (A1-4) water, (B1-4) saline, and (C1-4) phosphate-buffered saline (PBS) were determined by flow cytometry in the presence of antibodies to annexin V, IgG1-FITC, IgG1-APC, and IgG1-PE (left to right panels, respectively). Nanovesicle counts with annexin V binding buffer in (A5-8) water, (B5-8) saline, and (C5-8) PBS were determined by flow cytometry in the presence of antibodies to annexin V, IgG1-FITC, IgG1-APC, and IgG1-PE (left to right panels, respectively). (D) Quantitation of the nanovesicle results in the three different solutions with four different antibodies, with and without annexin $\mathrm{V}$ binding buffer. 


\section{Nano-sized vesicles and positive rates in different solutions following drug-induced apoptosis in K562 cells analyzed by flow cytometry}

The autophagy inhibitor elaiophylin $(0.2 \mu \mathrm{M})$ and the STAT3 inhibitor stattic $(10 \mu \mathrm{M})$ were used to induce apoptosis in K562 cells. After $24 \mathrm{~h}$ in serum-free medium, the percentages of total, early, and late apoptosis of K562 cells were $47.2 \pm 6.69,48.9 \pm 3.30$, and $35.8 \pm 3.32 \%$, and $40.1 \pm 3.81,11.4 \pm 10.0$, and $9.17 \pm 0.01 \%$ for elaiophylin and stattic, respectively $(n=3)$. The total, early, and late apoptosis percentages of control K562 cells (without elaiophylin and stattic) in serum-free medium for $24 \mathrm{~h}$ were $8.86 \pm 2.05 \%, 13.7 \pm 0.07 \%, 5.01 \pm 0.85 \%, 8.55$ $\pm 0.79 \%, 3.85 \pm 1.20 \%$, and $5.18 \pm 0.72 \%$, respectively $(\mathrm{n}=3)$ (Figure 7A).

Saline and PBS were used with the control, elaiophylin, and stattic groups. Equal numbers of MVs from the same group were dissolved in saline or PBS, with and without binding buffer. The counts of nano-sized vesicles in tubes containing PBS with binding buffer were significantly greater than the corresponding saline group $(\mathrm{n}=5, P<0.01)$ (Figure 7B) (Supplementary Table 2).

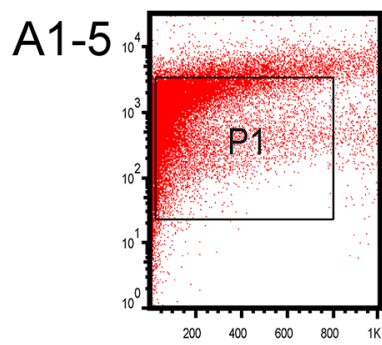

con saline

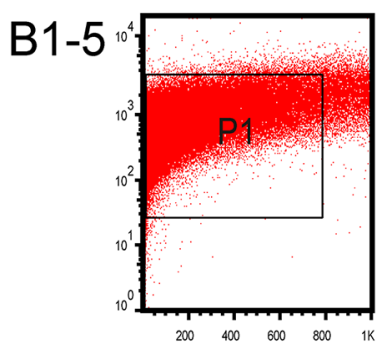

con PBS

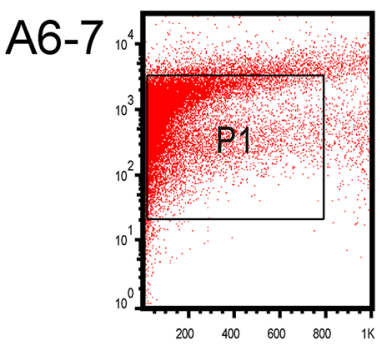

$\lg G$ PE saline

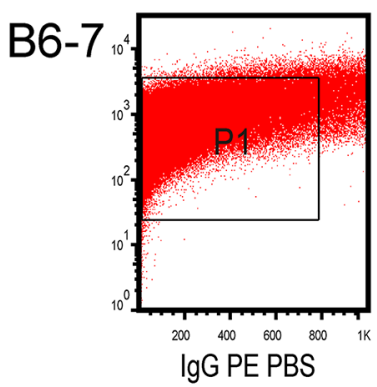

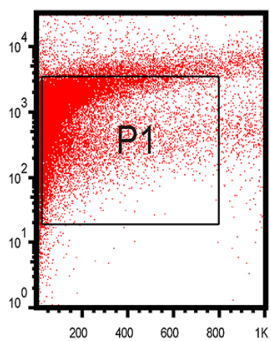

CD3 saline

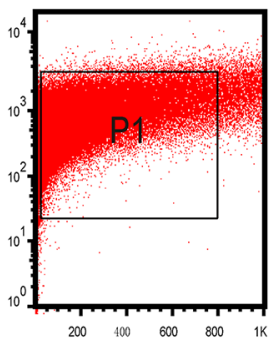

CD3 PBS

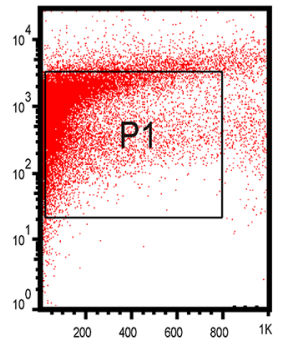

IgG APC saline

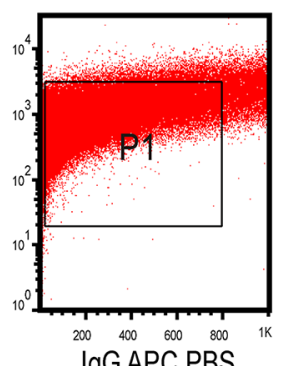

$\lg$ G APC PBS
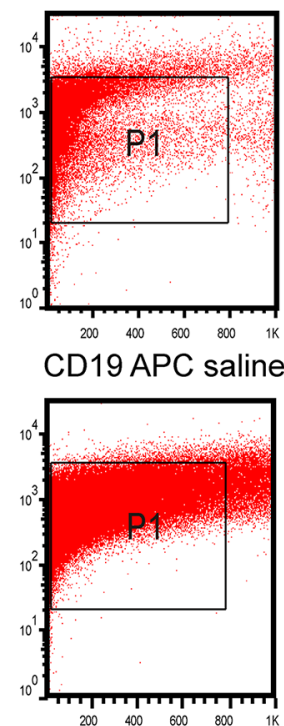

CD19 APC PBS

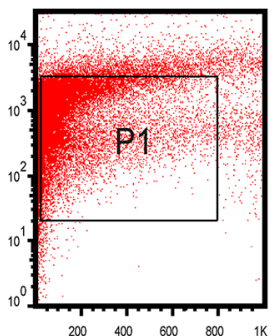

AnnexinV FITC saline

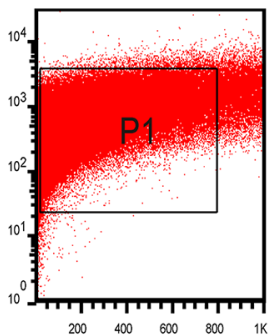

AnnexinV FITC PBS

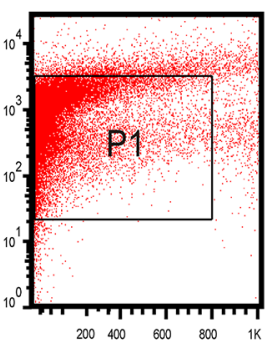

IgG FITC saline

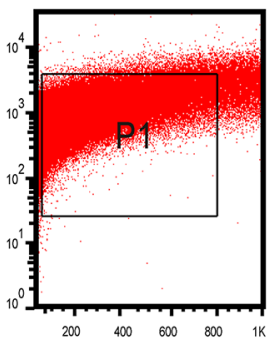

$\lg$ F FITC PBS
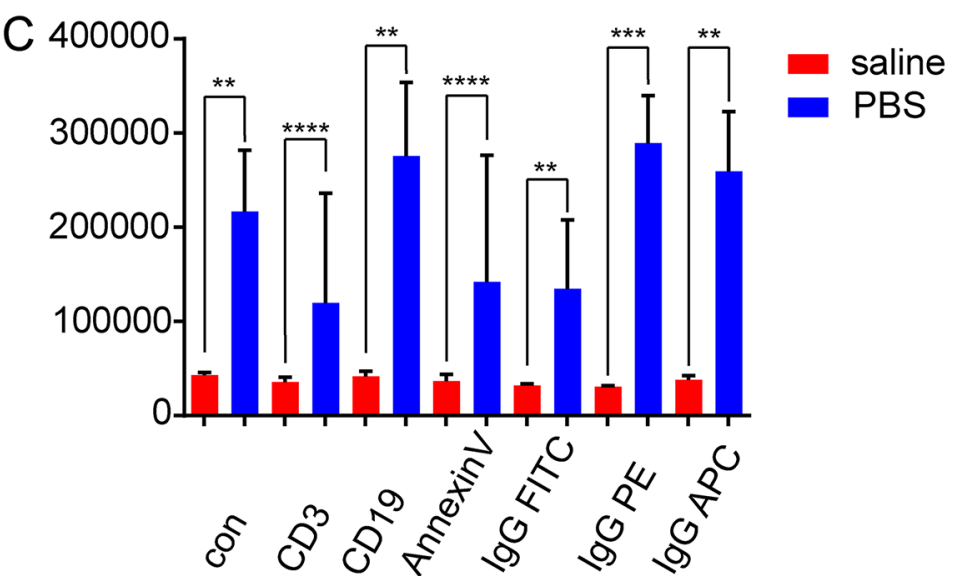

Figure 5: Effects of CD3, CD19, annexin V, and isotype control antibodies on nanovesicle counts. Nanovesicle counts generated with CD3, CD19, annexin V, and isotype control antibodies with annexin V binding buffer in (A1-7) saline and (B1-7) phosphatebuffered saline (PBS) were analyzed by flow cytometry. All numbering is left to right. (C) The quantitation of nanovesicle counts was determined by flow cytometry in saline and PBS with annexin V binding buffer. 
For analysis of the positive rate and the positive nano-sized counts, the control, elaiophylin, and stattic groups were dissolved in saline or PBS with binding buffer and annexin $\mathrm{V}$ antibody. The positive percentages were $63.8 \pm 5.83 \%, 68.5 \pm 4.93 \%, 69.6 \pm 4.32 \%, 70.7$ $\pm 3.11 \%, 60.6 \pm 8.06 \%$, and $77.1 \pm 4.12 \%$, respectively (Figure 7C). The positive nano-sized counts in the control, elaiophylin, and stattic groups dissolved in saline or PBS with binding buffer and annexin $\mathrm{V}$ antibody were 36,953 $\pm 3221,82,849 \pm 16383,50,840 \pm 3371,92,317 \pm 13,404$, $40,886 \pm 6557$, and $119,556 \pm 20,375$, respectively (Figure 7D) (Supplementary Table 3).

\section{DISCUSSION}

Intercellular communication is essential for cancer cells to survive and thrive. Extracellular vesicles such as exosomes, MVs, and large oncosomes are involved in this communication process by shuttling reciprocal signals and other molecules between cancer and stromal cells, including fibroblast, endothelial, and immune cells [15-17]. Extracellular vesicles could act as a platform for liquid biopsy in tumors, such as glioblastoma [3, 7 , $18,19]]$. In addition, increased numbers of $\mathrm{MVs}$ and the expression of specific MV markers such as CD19
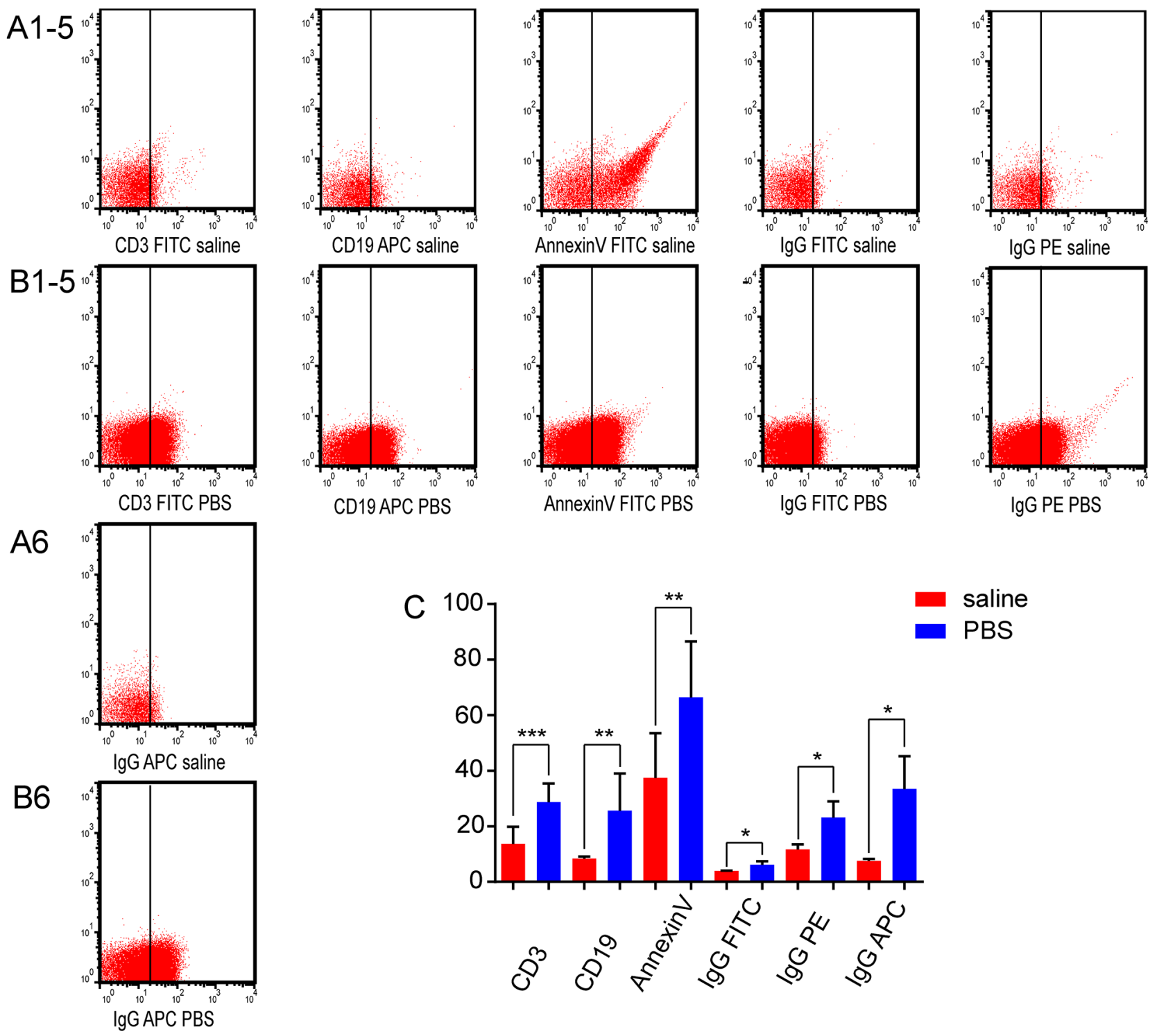

\section{saline PBS}

Figure 6: Effects of CD3, CD19, annexin V, and isotype control antibodies on the nanovesicle positive rate. CD3, $C D 19$, annexin $\mathrm{V}$, and isotype control positive rates with annexin V binding buffer in (A1-6) saline and (B1-6) PBS were analyzed by flow cytometry. All numbering is left to right. (C) The positive rates were analyzed by flow cytometry in saline and PBS with annexin V binding buffer. 
in chronic lymphocytic leukemia are associated with disease progression and malignancy [20]. Many studies have shown that increased circulating MVs indicate poor prognosis and disease progression in some cancers [20]. Thus, precise enumeration of MVs is very important in this area.

MVs are defined as particles between 100 and 1000 $\mathrm{nm}$ in diameter that typically exhibit PS on the outer leaflet of their plasma membranes. Most studies have shown that MVs are typed and identified by fluorescence-activated cell sorting. Because exposure of PS is a typical marker for MVs, the standard procedure is to stain PS exposed on the external surface with annexin V [21-23]. Apoptotic bodies are also derived from the membrane of parental cells, with PS exposed on the surface. As a result, the methods of detection are similar for MVs and apoptotic bodies. Annexin V binding to PS is calcium-dependent [24], which leads to a lack of sensitivity and specificity when used to define MV populations $[23,25]$. When using annexin $\mathrm{V}$ to define MVs, calcium-phosphate microprecipitates are observed in the MV gate and they increase the nonspecific binding of annexin $\mathrm{V}$, potentially leading to false-positive detection of MVs. Reporting increased MV-like microprecipitates might provide clinicians with erroneous information and misdiagnosis of diseases. Larson et al. designed an experiment showing that PBS generated an increasing amount of calcium-phosphate microprecipitates with increasing concentrations of $\mathrm{CaCl}_{2}$. Similar to our findings, they also found that the median fluorescence signal intensity increased with increasing $\mathrm{CaCl}_{2}$ concentrations when adding fluorescently labeled antibodies to the microprecipitates [22].

In our study, we confirmed that annexin $\mathrm{V}$ binding buffer contained $\mathrm{Ca}^{2+}$ and, when added to PBS, generated microprecipitates that led to false positive results. Thus, PBS was not suitable for MV counting. Resuspending the MV pellet in $100 \mu \mathrm{L}$ of saline could avoid artifacts from the calcium-phosphate microprecipitates, and falsepositive results. Saline appears to be a better choice to improve the sensitivity of MV-based lipid biopsy and provides important information about optimal molecular monitoring schedules in cancer diagnosis and evaluating the efficacy of different treatments. Exosomes, with a diameter of $100 \mathrm{~nm}$, could not be detected by flow

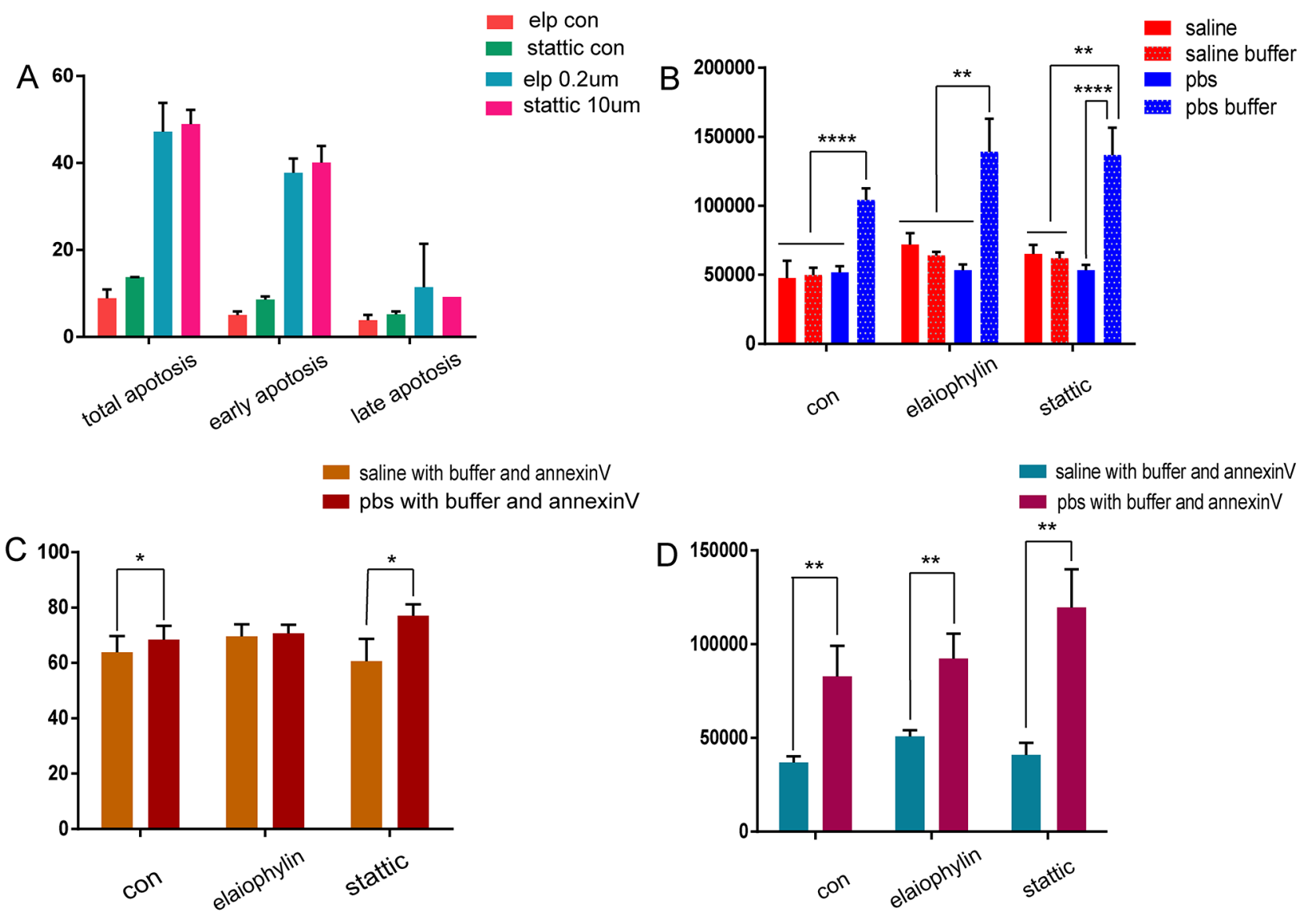

Figure 7: Annexin V positive rates and nano-sized vesicle counts in different solutions following drug-induced apoptosis in K562 cells analyzed by flow cytometry. (A) Flow cytometry analysis of apoptosis induced by elaiophylin and stattic in K562 cells. (B) Nanovesicle counts, (C) annexin V positive rates, and (D) annexin V positive nanovesicle counts generated from the drug-induced apoptosis of K562 cell with annexin V binding buffer in saline or PBS. 
cytometry because the lower limit of detection was 300 $\mathrm{nm}$. Thus, we consider that PBS will not affect exosome counts.

\section{MATERIALS AND METHODS}

\section{Cell culture and isolation of MVs}

The human chronic myeloid leukemia blast crisis cell line, K562, was purchased from the American Type Culture Collection (Manassas, VA, USA). HUVECs were obtained from the cell bank of the Chinese Academy of Sciences. K562 cells were cultured in RPMI 1640 medium containing $10 \%$ fetal bovine serum at $37^{\circ} \mathrm{C}$ in $5 \% \mathrm{CO}_{2}$. Before isolation of MVs, K562 cells were adjusted to $1 \times 10^{6} / \mathrm{mL}$ and cultured in serum-free RPMI 1640 for $4 \mathrm{~h}$. Cells were pelleted at $100 \times g$ for 5 min followed by centrifuging the supernatant at $3000 \times g$ for $10 \mathrm{~min}$ to remove cellular debris. The resultant supernatant was centrifuged at $5000 \times g$ for $30 \mathrm{~min}$ to remove smaller cellular debris, followed by centrifugation at $16,000 \times g$ for 90 min to obtain MVs [26]. HUVECs were cultured in DMEM medium containing $10 \%$ fetal bovine serum at $37^{\circ} \mathrm{C}$ in $5 \% \mathrm{CO}_{2}$.

\section{Labeling of MVs with PKH26 and PKH67}

MVs were labeled with PKH26 red and PKH67 green fluorescent cell linker mini kits (Sigma-Aldrich, St. Louis, MO, USA) following the manufacturer's instructions. MVs were visualized under a fluorescence microscope.

\section{Antibodies and reagents}

Monoclonal antibodies (CD3-FITC, CD19$\mathrm{APC}$, and annexin V-FITC) were purchased from BD Biosciences (Franklin Lakes, NJ, USA). Appropriate APC, $\mathrm{PE}$, and FITC isotype antibodies were used as negative controls (BD Biosciences). The fluorescent nanoparticle size standard kit was purchased from Spherotech (Lake Forest, IL, USA; Cat. No. NFPPS-52-4K). Elaiophylin was provided by North China Pharmaceutical Group Corporation New Drug R\&D center. Stattic was purchased from Sigma-Aldrich.

\section{Labeling of MVs and flow cytometric analyses}

All analyses were performed on an LSR II flow cytometer (BD Biosciences) with DIVA (BD Biosciences) and FlowJo software [17]. The MV gate was established based on forward and side scatters [27] using fluorescent microbeads of $0.22,0.45,0.88$, and $1.34 \mu \mathrm{m}$ diameters, and defining MVs as events less than $1.34 \mu \mathrm{m}$. The lower detection limit as a threshold above the electronic noise of the flow cytometer was $0.3 \mu \mathrm{m}$ [14]. To reduce background event numbers that affected the experimental results, the PBS, saline $(0.9 \% \mathrm{w} / \mathrm{v} \mathrm{NaCl})$, and annexin $\mathrm{V}$ binding buffers were double filtered through a $0.22-\mu \mathrm{m}$ filter (EMD Millipore, Billerica, MA, USA) and stored at $4^{\circ} \mathrm{C}$. Two groups of MVs were isolated from $40 \mathrm{~mL}$ of culture medium containing $1 \times 10^{6} / \mathrm{mL}$ of K562 cells, and diluted in $1 \mathrm{~mL}$ of double filtered saline or PBS. MVs were suspended by agitating for $5 \mathrm{~s}$ in a whirlpool oscillator, and a $100-\mu \mathrm{L}$ sample was aspirated into different flow tubes.

Two blank groups were designed using fluorescent nanoparticles to confirm the MV gate, each with three subgroups: double filtered water, saline, and PBS without MVs. The volume of each tube was $100 \mu \mathrm{L}$. To determine whether PBS mixed with annexin $\mathrm{V}$ binding buffer generated nano-sized vesicles, the annexin $V$ antibody was only added to tubes without the $10 \times$ annexin $\mathrm{V}$ binding buffer. In another blank group, the annexin $\mathrm{V}$ isotypematched control IgG1-FITC, IgG1-APC, and IgG1-PE antibodies were added at $10,6,5$, and $5 \mu \mathrm{L}$, respectively, with and without annexin $\mathrm{V}$ binding buffer. In the MV group, $6 \mu \mathrm{L}$ of CD3, $5 \mu \mathrm{L}$ of CD19, $6 \mu \mathrm{L}$ of IgG1-FITC, 5 $\mu \mathrm{L}$ of IgG1-APC, $5 \mu \mathrm{L}$ of IgG1-PE, and $10 \mu \mathrm{L}$ of annexin $\mathrm{V}$ antibodies were added into the same solutions (saline and PBS) with and without annexin V binding buffer. All antibodies added to the MV and blank groups were incubated for $30 \mathrm{~min}$ at room temperature in the dark. Event numbers of equal sample volumes were counted for $30 \mathrm{~s}$.

\section{Statistical analyses}

All statistical analyses were carried out using GraphPad Prism version 6.0 (GraphPad, La Jolla, CA, USA) and SPSS for Windows, version 17.0 (IBM, Chicago, IL, USA). Non-parametric and unpaired t-test comparisons were used to compare groups; the rates between groups were compared by the chi-square test. Two-sided $P<0.05$ was defined as being statistically significant.

\section{ACKNOWLEDGMENTS}

We thank Dr. Zhang Qian from the Blood Laboratory, Tongji Hospital, Tongji Medical College, Huazhong University of Science and Technology, for assistance in the acquisition of flow cytometry data.

\section{CONFLICTS OF INTEREST}

The authors declare no conflicts of interests.

\section{GRANT SUPPORT}

The work was supported by a grant from the National Natural Science Foundation of China (No.81500136). 


\section{REFERENCES}

1. Baj-Krzyworzeka M, Szatanek R, Weglarczyk K, Baran J, Urbanowicz B, Brański P, Ratajczak MZ, Zembala M. Tumour-derived microvesicles carry several surface determinants and mRNA of tumour cells and transfer some of these determinants to monocytes. Cancer Immunol Immunother. 2006; 55:808-18.

2. Jorfi S, Inal JM. The role of microvesicles in cancer progression and drug resistance. Biochem Soc Trans. 2013; 41:293-8.

3. Mahmoudi K, Ezrin A, Hadjipanayis C. Small extracellular vesicles as tumor biomarkers for glioblastoma. Mol Aspects Med. 2015; 45:97-102.

4. Muralidharan-Chari V, Clancy JW, Sedgwick A, D'SouzaSchorey C. Microvesicles: mediators of extracellular communication during cancer progression. J Cell Sci. 2010; 123:1603-11.

5. Ratajczak J, Miekus K, Kucia M, Zhang J, Reca R, Dvorak P, Ratajczak MZ. Embryonic stem cell-derived microvesicles reprogram hematopoietic progenitors: evidence for horizontal transfer of mRNA and protein delivery. Leukemia. 2006; 20:847-56.

6. Muralidharan-Chari V, Kohan HG, Asimakopoulos AG, Sudha T, Sell S, Kannan K, Boroujerdi M, Davis PJ, Mousa SA. Microvesicle removal of anticancer drugs contributes to drug resistance in human pancreatic cancer cells. Oncotarget. 2016; 7:50365-50379. doi: 10.18632/oncotarget.10395.

7. Skog J, Würdinger T, van Rijn S, Meijer DH, Gainche L, Sena-Esteves M, Curry WT JR, Carter BS, Krichevsky AM, Breakefield XO. Glioblastoma microvesicles transport RNA and proteins that promote tumour growth and provide diagnostic biomarkers. Nat Cell Biol. 2008; 10:1470-6.

8. Zappulli V, Friis KP, Fitzpatrick Z, Maguire CA, Breakefield XO. Extracellular vesicles and intercellular communication within the nervous system. J Clin Invest. 2016; 126:1198-207.

9. Soekmadji C, Riches JD, Russell PJ, Ruelcke JE, McPherson S, Wang C, Hovens CM, Corcoran NM, The Australian Prostate Cancer Collaboration BioResource, Hill MM, Nelson CC. Modulation of paracrine signaling by CD9 positive small extracellular vesicles mediates cellular growth of androgen deprived prostate cancer. Oncotarget. 2016 Aug 8. doi: 10.18632/oncotarget.11111. [Epub ahead of print].

10. György B, Módos K, Pállinger E, Pálóczi K, Pásztói M, Misják P, Deli MA, Sipos A, Szalai A, Voszka I, Polgár A, Tóth K, Csete M, et al. Detection and isolation of cell-derived microparticles are compromised by protein complexes resulting from shared biophysical parameters. Blood. 2011; 117:e39-48.

11. Rieseberg M, Kasper C, Reardon KF, Scheper T. Flow cytometry in biotechnology. Appl Microbiol Biotechnol. 2001;56:350-60.
12. van der Vlist EJ, Nolte-'t Hoen EN, Stoorvogel W, Arkesteijn GJ, Wauben MH. Fluorescent labeling of nanosized vesicles released by cells and subsequent quantitative and qualitative analysis by high-resolution flow cytometry. Nat Protoc. 2012; 7:1311-26.

13. Lacroix R, Robert S, Poncelet P, Dignat-George F. Overcoming limitations of microparticle measurement by flow cytometry. Semin Thromb Hemost. 2010; 36:807-18.

14. Crompot E, Van Damme M, Duvillier H, Pieters K, Vermeesch M, Perez-Morga D, Meuleman N, Mineur P, Bron D, Lagneaux L, Stamatopoulos B. Avoiding false positive antigen detection by flow cytometry on blood cell derived microparticles: the importance of an appropriate negative control. PLoS One. 2015; 10:e0127209.

15. Boelens MC, Wu TJ, Nabet BY, Xu B, Qiu Y, Yoon T, Azzam DJ, Twyman-Saint Victor C, Wiemann BZ, Ishwaran H, Ter Brugge PJ, Jonkers J, Slingerland J, Minn AJ. Exosome transfer from stromal to breast cancer cells regulates therapy resistance pathways. Cell. 2014; 159:499-513.

16. Kanada M, Bachmann MH, Hardy JW, Frimannson DO, Bronsart L, Wang A, Sylvester MD, Schmidt TL, Kaspar RL, Butte MJ, Matin AC, Contag CH. Differential fates of biomolecules delivered to target cells via extracellular vesicles. Proc Natl Acad Sci U S A. 2015; 112:E1433-42.

17. Zhou J, Ghoroghi S, Benito-Martin A, Wu H, Unachukwu UJ, Einbond LS, Guariglia S, Peinado H, Redenti S. Characterization of Induced Pluripotent Stem Cell Microvesicle Genesis, Morphology and Pluripotent Content. Sci Rep. 2016; 6:19743.

18. Santiago-Dieppa DR, Steinberg J, Gonda D, Cheung VJ, Carter BS, Chen CC. Extracellular vesicles as a platform for 'liquid biopsy' in glioblastoma patients. Expert Rev Mol Diagn. 2014; 14:819-25.

19. Moon PG, Lee JE, Cho YE, Lee SJ, Chae YS, Jung JH, Kim IS, Park HY, Baek MC. Fibronectin on circulating extracellular vesicles as a liquid biopsy to detect breast cancer. Oncotarget. 2016; 7:40189-40199. doi: 10.18632/ oncotarget.9561.

20. Ghosh AK, Secreto CR, Knox TR, Ding W, Mukhopadhyay D, Kay NE. Circulating microvesicles in B-cell chronic lymphocytic leukemia can stimulate marrow stromal cells: implications for disease progression. Blood. 2010; 115:1755-64.

21. Shi J, Shi Y, Waehrens LN, Rasmussen JT, Heegaard CW, Gilbert GE. Lactadherin detects early phosphatidylserine exposure on immortalized leukemia cells undergoing programmed cell death. Cytometry A. 2006; 69:1193-201.

22. Larson MC, Luthi MR, Hogg N, Hillery CA. Calciumphosphate microprecipitates mimic microparticles when examined with flow cytometry. Cytometry A. 2013; $83: 242-50$ 
23. Iversen LV, Ostergaard $\mathrm{O}$, Nielsen $\mathrm{CT}$, Jacobsen $\mathrm{S}$, Heegaard NH. A heparin-based method for flow cytometric analysis of microparticles directly from platelet-poor plasma in calcium containing buffer. J Immunol Methods. 2013; 388:49-59.

24. van der Heyde HC, Gramaglia I, Combes V, George TC, Grau GE. Flow cytometric analysis of microparticles. Methods Mol Biol. 2011; 699:337-54.

25. Connor DE, Exner T, Ma DD, Joseph JE. The majority of circulating platelet-derived microparticles fail to bind annexin V, lack phospholipid-dependent procoagulant activity and demonstrate greater expression of glycoprotein Ib. Thromb Haemost. 2010; 103:1044-52.
26. Zhu X, You Y, Li Q, Zeng C, Fu F, Guo A, Zhang H, Zou P, Zhong Z, Wang H, Wu Y, Li Q, Kong F, Chen Z. BCR-ABL1-positive microvesicles transform normal hematopoietic transplants through genomic instability: implications for donor cell leukemia. Leukemia. 2014; 28:1666-75.

27. Caivano A, Laurenzana I, De Luca L, La Rocca F, Simeon V, Trino S, D'Auria F, Traficante A, Maietti M, Izzo T, D'Arena G, Mansueto G, Pietrantuono G, et al. High serum levels of extracellular vesicles expressing malignancyrelated markers are released in patients with various types of hematological neoplastic disorders. Tumour Biol. 2015; 36:9739-52. 